\title{
Initial Energy for External Electrical Cardioversion of Atrial Fibrillation
}

\author{
Edilberto Figueiredo, Henrique Horta Veloso, Angelo Amato Vincenzo de Paola, \\ pelos Investigadores da SOCESP \\ São Paulo, SP - Brazil
}

\begin{abstract}
Objective - To investigate the initial energy level required for electrical cardioversion of atrial fibrillation $(A F)$.
\end{abstract}

Methods - We studied patients undergoing electrical cardioversion in the 1st Multicenter Trial of SOCESP. Patients were divided into 2 groups according to the initial energy level of electrical cardioversion: $100 \mathrm{~J}$ and $\geq 150 \mathrm{~J}$. We compared the efficacy of the initial and final shock of the procedure, the number of shocks administered, and the cumulative energy levels.

Results - Eight-six patients underwent electrical cardioversion. In 53 patients (62\%), cardioversion was started with $100 \mathrm{~J}$, and in 33 patients (38\%), cardioversion was started with $\geq 150 J$. Groups did not differ regarding clinical features and therapeutical interventions. A tendency existed towards greater efficacy of the initial shock in patients who received $\geq 150 J(61 \%$ vs. $42 \%$ in the $100 J$ group, $p=0.08)$. The number of shocks was smaller in the $\geq 150 J$ group $(1.5 \pm 0.7 \mathrm{vs}$. 2.1 1 1.3, $p=0.04)$. No difference existed regarding the final efficacy of electrical cardioversion and total cumulative energy levels in both groups. In the subgroup of patients with recent-onset $A F$ $(\leq 48 \mathrm{~h})$, the cumulative energy level was lower in the $100 \mathrm{~J}$ group (240 $\pm 227 J v s .324 \pm 225 J$, $p=0.03)$.

Conclusion - Patients who were given initial energy of $\geq 150 J$ received fewer counter shocks with a tendency toward greater success than those patients who were given $100 J$; however, in patients with recent-onset AF, the average cumulative energy level was lower in the 100J group. These data suggest that electrical cardioversion should be initiated with energy levels $\geq 150$ J in patients with chronic AF.

Key words: atrial fibrillation, arrhythmia, electrical cardioversion

Universidade Federal de São Paulo - Escola Paulista de Medicina

Mailing address: Henrique Horta Veloso - Setor de Eletrofisiologia Clínica - UNIFESP Rua Napoleão de Barros, 593 - 04024-002 - São Paulo, SP - E-mail: hhorta@cardiol.br
Direct-current electrical cardioversion is one of the most widely used methods for restoration of sinus rhythm in patients with atrial fibrillation. Since its introduction by Lown et al ${ }^{1}$ in 1962, it has been considered safe and effective, with expected success rates around $50 \%$ with a $100 \mathrm{~J}$ initial shock and around $50 \%$ and $80 \%$ with a $200 \mathrm{~J}$ initial shock ${ }^{2}$. Complications, such as postcardioversion arrhythmia, that vary from extrasystoles and bradycardias to ventricular fibrillation $^{3-5}$, myocardial injury ${ }^{6}$, coronary spasms ${ }^{7}$, as well as the complications related to sedation ${ }^{8}$ may seldom occur. Despite the widespread use in clinical practice, no consensus exists on what should be the initial energy level for elective electrical cardioversion of persistent atrial fibrillation.

\section{Methods}

The 1st Multicenter Study of the Sociedade de Cardiologia do Estado de São Paulo (SOCESP) (The Cardiology Society of State of São Paulo) on the treatment of atrial fibrillation was composed by 2 phases. In the 1 st phase, the cost/effective ratio of electrical cardioversion versus pharmacological cardioversion ${ }^{8,9}$ was compared, and, in the 2 nd phase, we compared the efficacy and safety of sotalol versus quinidine for the maintenance of sinus rhythm after atrial fibrillation ${ }^{10,11}$ reversion. The ethical committees of all services involved approved the study protocol, according to the recommendations of the World Health Organization and the Helsinki declaration of 1975 for biomedical research involving human beings. After informed consent was obtained, patients were randomly assigned to undergo pharmacological or electrical cardioversion, using drugs and energy levels according to the experience of each center. The anesthetic used for electrical cardioversion, as well as the number of shocks and the energy administered, were left to the discretion of each investigator. Likewise, the type and dosage of antiarrhythmic drugs used for pharmacological cardioversion was also up to the investigator. In case of failure during pharmacological cardioversion, the investigator could attempt electrical cardioversion. The decision regar- 
ding anticoagulation before cardioversion was also left up to the investigators, but it was strongly recommended that anticoagulation be used in patients with a high risk for thromboembolic events.

The study included clinically stable patients with atrial fibrillation of up to 6-months of duration. Exclusion criteria included hypokalemia (potassium serum $\leq 3.8 \mathrm{mEq} / \mathrm{L}$ ), any anesthetic contraindication, digitalis toxicity, congestive heart failure (New York Heart Association class III or IV), ventricular frequency lower than $50 \mathrm{bpm}$, diastolic blood pressure $>110 \mathrm{mmHg}$, alcohol and drug abuse, pregnancy or nursing, renal failure, myocardial infarction in less than 30 days, left ventricular ejection fraction lower than $40 \%$, and the presence of diseases that could put the patient at risk. We avoided including patients with left atrium diameter greater than $5.2 \mathrm{~cm}$ on the echocardiogram with the purpose of selecting candidates eligible both for electrical and pharmacological cardioversion.

In the present study, we assessed only the group of 86 patients undergoing electrical cardioversion. Variables assessed were the efficacy of initial and final shock of electrical cardioversion, the number of shocks administered, and the total cumulative energy level. Patients were divided into 2 groups according to the initial energy level of cardioversion: $100 \mathrm{~J}$ and $\geq 150 \mathrm{~J}$. If atrial fibrillation had been present for less than 48 hours, we defined it as recent-onset, and we defined arrhythmia that lasted more than 48 hours as chronic atrial fibrillation.

Variables studied are expressed as mean \pm standard deviation and median, besides maximum and minimum values. We compared dichotomous variables using the chisquare test or, when Cochran restrictions were present, we used the Fisher exact test. Continuous variables were compared using the Mann-Whitney test. All tests were 2-tailed, and a $p$ value $<0.05$ was considered significant.

\section{Results}

Restoration of sinus rhythm was obtained in 65 of the 86 patients who underwent external electrical cardioversion, with a success rate of $76 \%$. The most frequently used drug for sedation of cardioversion was thiopentone sodium in $43 \%$ of the cases, which was administered alone or in association with midazolam (tab. I). Severe complications were not observed in either of the groups studied

Fifty-three patients $(62 \%)$ received an initial shock of $100 \mathrm{~J}$, and 33 patients $(38 \%)$ received an initial shock of $\geq 150 \mathrm{~J}$ (16 patients received shocks of $150 \mathrm{~J}$, and 17 patients received shocks of 200J). Clinical and laboratory features of the patients are presented in table II. No significant difference was observed in the groups regarding clinical characteristics or left atrium diameter.

Anticoagulation was not used in 44 patients with recent-onset atrial fibrillation. Among 42 patients with chronic atrial fibrillation, 29 patients in whom arrhythmia had been present for more than 7 days and 4 of 12 patients (30\%) who experienced atrial fibrillation from 48 hours to 7 days

\begin{tabular}{|c|c|}
\hline \multicolumn{2}{|c|}{$\begin{array}{c}\text { Table I - Scheme of drugs used for sedation for electrical } \\
\text { cardioversion }\end{array}$} \\
\hline Drug & Total \\
\hline thiopental sodium & $35(41 \%)$ \\
\hline thiopental sodium + midazolam & $2(2 \%)$ \\
\hline etomidate + fentanyl citrate & $20(23 \%)$ \\
\hline etomidate & $12(14 \%)$ \\
\hline etomidate + midazolam & $1(1 \%)$ \\
\hline midazolam & $10(12 \%)$ \\
\hline propofol & $5(6 \%)$ \\
\hline propofol + fentanyl citrate & $1(1 \%)$ \\
\hline Total & $86(100 \%)$ \\
\hline
\end{tabular}

\begin{tabular}{|c|c|c|c|}
\hline \multicolumn{4}{|c|}{$\begin{array}{c}\text { Table II - Clinical characteristics of patients studied according to } \\
\text { initial shock energy level }\end{array}$} \\
\hline Variable & $\begin{array}{l}\text { Group } 100 \mathrm{~J} \\
\quad(\mathrm{n}=53)\end{array}$ & $\begin{array}{l}\text { Group } \geq 150 \mathrm{~J} \\
\quad(\mathrm{n}=33)\end{array}$ & $\mathrm{p}$ \\
\hline Age (years) & $56 \pm 12$ & $57 \pm 14$ & 0.92 \\
\hline Men & $28(53 \%)$ & $19(58 \%)$ & 0.67 \\
\hline Duration of $\mathrm{AF}>48 \mathrm{~h}$ & $30(57 \%)$ & $12(36 \%)$ & 0.07 \\
\hline Left atrium $(\mathrm{cm})$ & $4,3 \pm 0,7$ & $4,2 \pm 0,8$ & 0.85 \\
\hline Lone AF & $22(42 \%)$ & $8(24 \%)$ & 0.10 \\
\hline Blood hypertension & $21(40 \%)$ & $14(42 \%)$ & 0.80 \\
\hline NYHA Functional Class II & $10(19 \%)$ & $2(6 \%)$ & 0.12 \\
\hline $\begin{array}{l}\text { Previous use of } \\
\text { antiarrhythmic drugs }\end{array}$ & $12(23 \%)$ & $7(21 \%)$ & 0.88 \\
\hline Quinidine & $4(8 \%)$ & 0 & 0.11 \\
\hline Quinidine + digitalis & $3(6 \%)$ & $2(6 \%)$ & 0.65 \\
\hline Procainamide & $2(4 \%)$ & $4(12 \%)$ & 0.35 \\
\hline Amiodarone & $3(6 \%)$ & $1(3 \%)$ & 0.64 \\
\hline
\end{tabular}

received anticoagulation medication. No cases of thromboembolism occurred.

The immediate success rate for cardioversion was $42 \%$ ( 22 of 53 patients) in the group who received an initial energy shock of $100 \mathrm{~J}$ and $61 \%$ in the group that received initial energy of ${ }^{3} 150 \mathrm{~J}$ ( 20 of 33 patients) (tab. IV). Patients who received higher levels of initial energy experienced greater restoration of sinus rhythm in the first shock $(p=0.08)$. Of the 33 patients from the $\geq 150 \mathrm{~J}$ group, the initial shock was effective in 10 of the 16 patients $(62 \%)$ treated with $150 \mathrm{~J}$ and 10 of the 17 patients that received $200 \mathrm{~J}(59 \%)(\mathrm{p}=0.83)$.

The total success rate after the last attempt at cardioversion was $75 \%$ (40 of 53 patients) in the $100 \mathrm{~J}$ group and $76 \%$ in the $\geq 150 \mathrm{~J}$ group ( 25 of 33 patients) $(\mathrm{p}=0.98$ ). Cumulative success rates for each energy level are presented in figure 1 . More substantial increases in success rate of $0.25 \% / \mathrm{J}$, occurred between $100 \mathrm{~J}$ and $200 \mathrm{~J}$, and were only $0.06 \% / \mathrm{J}$ for energy levels greater than $200 \mathrm{~J}$.

Electrical cardioversion was not successful in 24 patients, 7 patients $(33 \%)$ received maximum energy of $200 \mathrm{~J}, 4$ patients $(19 \%)$ received $250 \mathrm{~J}, 6$ patients $(29 \%)$ received $300 \mathrm{~J}$, and 4 patients $(19 \%)$ received $360 \mathrm{~J}$.

In 29 patients (34\%), cardioversion was unsuccessful with energy levels $\leq 250 \mathrm{~J}$. Eleven of them (38\%) did not receive energy $\geq 300 \mathrm{~J}$. In 18 patients $(62 \%)$ in whom energy levels of 300 and $360 \mathrm{~J}$ were used, cardioversion was achieved in 8 patients $(44 \%)$. 


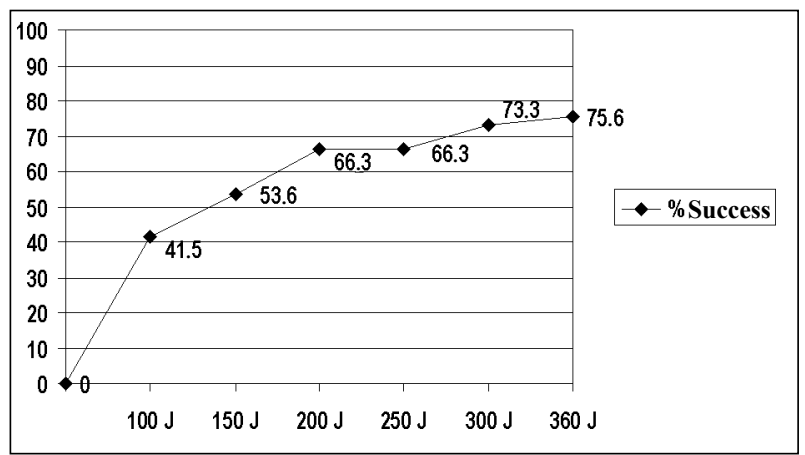

Fig. 1 - Cumulative success rates according to the energy level of shocks administered in electrical cardioversion.

The total number of shocks administered was significantly smaller in the $\geq 150 \mathrm{~J}$ group compared with that in the $100 \mathrm{~J}$ group ( $1.5 \pm 0.7$ versus $2.1 \pm 1.3$, respectively, $\mathrm{p}=0.04$ ). Total cumulative energy did not differ between the groups (tab. III).

Regarding the presence of structural heart disease,

\begin{tabular}{|c|c|c|c|}
\hline \multicolumn{4}{|c|}{$\begin{array}{l}\text { Table III - Comparison of electrical cardioversion among } \\
\text { patients according to initial shock energy level }\end{array}$} \\
\hline $\begin{array}{l}\text { Variable } \\
\qquad(\mathrm{n}=53)\end{array}$ & $\begin{array}{l}\text { Group } 100 \mathrm{~J} \\
(\mathrm{n}=33)\end{array}$ & Group $\geq 150 \mathrm{~J}$ & $\mathrm{p}$ \\
\hline Success with initial shock & $22(42 \%)$ & $20(61 \%)$ & 0.08 \\
\hline Final success of ECV & $40(75 \%)$ & $25(76 \%)$ & 0.98 \\
\hline Number of shocks & & & $0.04 *$ \\
\hline Mean \pm SD & $2.1 \pm 1.3$ & $1.5 \pm 0.7$ & \\
\hline Median & 2 & 1 & \\
\hline Variation & $1-6$ & $1-3$ & \\
\hline Cumulative energy (J) & & & 0.30 \\
\hline Mean \pm SD & $348 \pm 337$ & $317 \pm 202$ & \\
\hline Median & 250 & 200 & \\
\hline Variation & $100-1470$ & $150-860$ & \\
\hline
\end{tabular}

the final efficacy of electrical cardioversion and initial sho$\mathrm{ck}$, as well as the number of shocks administered, and the total cumulative energy levels did not differ between the $100 \mathrm{~J}$ and the $\geq 150 \mathrm{~J}$ groups, either in patients with "lone" atrial fibrillation or in patients with underlying heart disease (tab.IV).

In patients with recent-onset atrial fibrillation, total cumulative energy was smaller in the 100J group in comparison with that in the $\geq 150 \mathrm{~J}$ group $(240 \pm 227 \mathrm{~J}$ versus $324 \pm 225 \mathrm{~J}$, respectively, $\mathrm{p}=0.03$ ), with no differences regarding the efficacy of the final and initial shock and the number of shocks administered. In patients with chronic atrial fibrillation, the number of shocks was smaller in the $\geq 150 \mathrm{~J}$ group compared with that in the $100 \mathrm{~J}$ group $(1.5 \pm 0.7$ versus $2.4 \pm 1.4$, respectively, $\mathrm{p}=0.04$ ), with no differences regarding the efficacy of the initial shock, total cumulative energy, and cardioversion for sinus rhythm (tab. IV).

\section{Discussion}

The $76 \%$ final success rate of electrical cardioversion is less than that previously reported in the literature. However, results are difficult to compare when clinical characteristics vary in the several studies. In our study, the electrical cardioversion procedure was not standardized. It was up to each center, so it may reflect the preference of the main Cardiology centers in the State of São Paulo. The use of different energy schedules, as well as the use of different defibrillators and paddle electrodes in each study center, may have influenced the final results of the procedure.

Pretreatment with antiarrhythmic drugs in only $22 \%$ of the patients has directly influenced cardioversion rates. Randomized studies show that previous use of antiarrhythmic drugs enhances the efficacy of electrical cardioversion or, at least, decreases early recurrence of atrial fibrillation ${ }^{12-15}$.

Electrical cardioversion had maximum energy levels

\begin{tabular}{|c|c|c|c|c|c|c|}
\hline \multirow{2}{*}{$\begin{array}{l}\text { Structural Heart Disease } \\
\text { Variable }\end{array}$} & \multicolumn{3}{|c|}{$\begin{array}{l}\text { Absent } \\
(\mathrm{n}=30)\end{array}$} & \multicolumn{3}{|c|}{$\begin{array}{l}\text { Present } \\
(\mathrm{n}=56)\end{array}$} \\
\hline & $\begin{array}{c}100 \mathrm{~J} \\
(\mathrm{n}=22)\end{array}$ & $\begin{array}{l}\geq 150 \mathrm{~J} \\
(\mathrm{n}=8)\end{array}$ & $\mathrm{p}$ & $\begin{array}{c}100 \mathrm{~J} \\
(\mathrm{n}=31)\end{array}$ & $\begin{array}{l}\geq 150 \mathrm{~J} \\
(\mathrm{n}=25)\end{array}$ & $\mathrm{p}$ \\
\hline Success of initial shock & $9(41 \%)$ & $6(75 \%)$ & 0.34 & $13(42 \%)$ & $14(56 \%)$ & 0.30 \\
\hline Final success of ECV & $17(77 \%)$ & $6(75 \%)$ & 0.62 & $23(74 \%)$ & $19(76 \%)$ & 0.88 \\
\hline Number of shocks & $2.2 \pm 1.5$ & $1.5 \pm 0.9$ & 0.17 & $2.0 \pm 1.1$ & $1.5 \pm 0.6$ & 0.13 \\
\hline Cumulative energy $(\mathrm{J})$ & $400 \pm 413$ & $300 \pm 236$ & 0.94 & $312 \pm 272$ & $323 \pm 195$ & 0.23 \\
\hline Duration of atrial fibrillation & \multicolumn{3}{|c|}{$\begin{array}{l}\text { Recent-onset }(\leq 48 \mathrm{~h}) \\
(\mathrm{n}=44)\end{array}$} & \multicolumn{3}{|c|}{$\begin{array}{c}\text { Chronic }(>48 \mathrm{~h}) \\
\quad(\mathrm{n}=42)\end{array}$} \\
\hline Variável & $\begin{array}{c}100 \mathrm{~J} \\
(\mathrm{n}=23)\end{array}$ & $\begin{array}{l}\geq 150 \mathrm{~J} \\
(\mathrm{n}=21)\end{array}$ & $\mathrm{p}$ & $\begin{array}{c}100 \mathrm{~J} \\
(\mathrm{n}=30)\end{array}$ & $\begin{array}{l}\geq 150 \mathrm{~J} \\
(\mathrm{n}=12)\end{array}$ & $\mathrm{P}$ \\
\hline Success of initial shock & $13(57 \%)$ & $13(62 \%)$ & 0.72 & $9(30 \%)$ & $7(58 \%)$ & 0.25 \\
\hline Final success of ECV & $20(87 \%)$ & $16(76 \%)$ & 0.55 & $20(67 \%)$ & $9(75 \%)$ & 0.72 \\
\hline Number of shocks & $1.7 \pm 0.9$ & $1.5 \pm 0.7$ & 0.73 & $2.4 \pm 1.4$ & $1.5 \pm 0.7$ & $0.04 *$ \\
\hline Cumulative energy (J) & $240 \pm 227$ & $324 \pm 225$ & $0.03 *$ & $431 \pm 385$ & $305 \pm 164$ & 0.77 \\
\hline
\end{tabular}


limited to 200 to $250 \mathrm{~J}$ in about $50 \%$ of the patients considered as unsuccessful, and to $300 \mathrm{~J}$ in $29 \%$ of these cases. Only $19 \%$ of the procedures depleted the possibilities of the method, using 360J of energy. Several studies had thresholds higher than $200 \mathrm{~J}$ in up to $74 \%$ of the cases ${ }^{16-18}$, and probably the success rate would increase if 300 to $360 \mathrm{~J}$ of energy were attempted in all cases considered unsuccessful. In our study, the use of $\geq 300 \mathrm{~J}$ of energy in the cases where previous $\leq 250$ J shocks had failed increased the cardioversion rate in $44 \%$ of patients. Therefore, if all the cases had undergone a $\geq 300$ J shock, we should expect 5 more cases of restoration of the sinus rhythm, resulting in a total cardioversion rate of $81 \%$ ( 70 of 86 patients).

In our study, the most frequently used initial energy was $100 \mathrm{~J}$ in $62 \%$ of the cardioversions performed. None of the cardioversions was initiated with energy levels $>200 \mathrm{~J}$. The $\geq 150 \mathrm{~J}$ group tended to be more successful compared with the $100 \mathrm{~J}$ group $(61 \%$ versus $42 \%, \mathrm{p}=0.08)$. In a nonrandomized study, Sermasi et al ${ }^{19}$ compared groups that received 100 and 200J of initial energy and observed that higher initial energy resulted in greater efficacy of the initial shock (36\% versus $13 \%$ ). Ricard et $\mathrm{al}^{20}$, in a nonrandomized prospective study in patients with atrial fibrillation lasting more than 24 hours, reported success rates of $22 \%, 48 \%$, $75 \%$, and $96 \%$ with 40 to $50 \mathrm{~J}, 80$ to $100 \mathrm{~J}, 160$ to $200 \mathrm{~J}$, and $360 \mathrm{~J}$, respectively. Joglar et al. ${ }^{21}$, in the only randomized study for the assessment of initial energy of elective cardioversion of atrial fibrillation, also had higher efficacy of shocks using higher initial energy levels: cardioversion rates were 14\% with $100 \mathrm{~J}, 39 \%$ with $200 \mathrm{~J}$, and $90 \%$ with $360 \mathrm{~J}$.

In our study, no differences existed between the groups regarding the final success of the procedure $(75 \%$ in the $100 \mathrm{~J}$ group and $76 \%$ in the $\geq 150 \mathrm{~J}$ group). Sermasi et al ${ }^{19}$ did not find differences in final cardioversion rates $(87 \%$ in the $100 \mathrm{~J}$ group and $85 \%$ in the $200 \mathrm{~J}$ group). Likewise, Joglar et al ${ }^{20}$ reported similar final efficacy between the groups studied (90\% in the 100 and $200 \mathrm{~J}$ groups and $100 \%$ in the 360J group).

We observed that, when cardioversion was started with 100J energy, a significantly greater number of shocks were administered $(2.1 \pm 1.3$ versus $1.5 \pm 0.7$ in the $\geq 150 \mathrm{~J}$ group). Joglar et al ${ }^{21}$ also noticed that the total number of shocks administered were was higher when initial energy levels were lower $(2.8 \pm 1.2$ with $100 \mathrm{~J} ; 2.2 \pm 1.4$ with $200 \mathrm{~J}$, and $1.1 \pm 0.5$ with $360 \mathrm{~J})$. The lower number of shocks administered in cardioversion is interesting especially because of a shorter sedation period, reducing risks like nausea, vomiting, and respiratory depression.

Significant differences were not found among the groups regarding total cumulative energy levels $(348 \pm 337 \mathrm{~J}$ in $100 \mathrm{~J}$ group versus $317 \pm 202 \mathrm{~J}$ in $\geq 150 \mathrm{~J}$ group). Sermasi et al ${ }^{19}$ observed that cumulative energy in the $100 \mathrm{~J}$ group was higher than that in the $200 \mathrm{~J}$ group (303 versus $440 \mathrm{~J})$. Joglar et al ${ }^{21}$ observed cumulative energy levels of $615 \pm 385 \mathrm{~J}$ in the $100 \mathrm{~J}$ group, $620 \pm 694 \mathrm{~J}$ in $200 \mathrm{~J}$ group, and $414 \pm 176 \mathrm{~J}$ in $360 \mathrm{~J}$ group, with significant differences between 100 and 360J groups $(p=0.04)$, and a tendency toward in differences between the
100 and $200 \mathrm{~J}$ groups $(\mathrm{p}=0.07)$, and no differences between the 100 and $200 \mathrm{~J}$ groups. Unlike high-energy shocks used during cardiopulmonary resuscitation, recent studies ${ }^{21-24}$ report that myocardium damage during electrical cardioversion of atrial fibrillation is minimal or absent.

In our study, those patients with recent-onset atrial fibrillation (lasting $\leq 48 \mathrm{~h}$ ) that received $100 \mathrm{~J}$ of energy had a cumulative energy significantly lower than that in those patients in the $\geq 150 \mathrm{~J}$ group. In patients with chronic atrial fibrillation (lasting $>48 \mathrm{~h}$ ), the number of shocks administered was lower in the $\geq 150 \mathrm{~J}$ group, similar to that in the total group. Although these data are limited due to the restricted number of patients in each subgroup, they are in accordance with previous studies that showed the relation between the immediate success of electrical cardioversion and the duration of arrhythmia ${ }^{20}$. The authors of this study concluded that $100 \mathrm{~J}$ of energy may be appropriate for patients with recent-onset atrial fibrillation (lasting $<24 \mathrm{~h}$ ); however, it can be very low for electrical cardioversion of patients with longer episodes of arrhythmia.

The recommendation regarding initial energy for external electrical cardioversion has gradually increased through the years. Recent recommendations for management of atrial fibrillation, such as the European and the Canadian consensus, have recommended an initial energy of $200 \mathrm{~J}^{25,26}$, despite the lack of evidence for this conduct. Additionally, some experts frequently use higher initial energy for cardioversion of atrial fibrillation ${ }^{27}$. However, guidelines still in use, such as those of the Advanced Cardiac Life Support of the American Heart Association, still recommend initial energy jolts of $100 \mathrm{~J}^{28}$.

The greatest limitation of our study is that randomization was not done with the purpose of assessing initial energy for electrical cardioversion. However, no significant difference existed regarding clinical and laboratory characteristics and previous treatment with antiarrhythmic drugs between the groups. Only an insignificant tendency existed in the $\geq 150 \mathrm{~J}$ group to experience a small number of chronic atrial fibrillation episodes. This fact could explain the differences found, with a reduction in the number of shocks and a tendency toward greater efficacy of the initial shock in the $\geq 150 \mathrm{~J}$ group. However, our data are in accordance with the studies that compared initial energy levels for elective electrical cardioversion of atrial fibrillation ${ }^{19-21}$.

No thromboembolic complications occurred. Only $30 \%$ of the patients with atrial fibrillation lasting 48 hours to 7 days received anticoagulation medication in our study. Despite the lack of evidence regarding the exact duration of atrial fibrillation that determines anticoagulation before electrical cardioversion ${ }^{25}$, current consensus recommend that all cases with arrhythmia lasting longer than 48 hours must receive anticoagulation medication ${ }^{25,26,29,30}$.

Finally, our study showed that, for external electrical cardioversion of atrial fibrillation, $\mathrm{a} \geq 150 \mathrm{~J}$ initial energy level is related to a smaller number of shocks and a tendency towards greater success in the first shock. The success rate with a standard $100 \mathrm{~J}$ initial energy level was very low. 
However, in the subgroup of patients with recent-onset atrial fibrillation, cumulative energy was lower in the $100 \mathrm{~J}$ group. We believe that, except for the patients with recentonset arrhythmia, higher energies should be considered in the first shock of external electrical cardioversion of atrial fibrillation.

\section{Acknowledgments}

We thank Dr. Luiz Olympio Teixeira Nascimento of the Medical Division of Bristol-Myers Squibb laboratory of Brazil S/A, for participating in the monitoring of this study.

\section{Participants of the phase 1 of the 1st Multicenter Trial of SOCESP}

Centers: 1) Escola Paulista de Medicina - UNIFESP: Angelo A.V. de Paola, Edilberto Figueiredo, Henrique H.
Veloso; 2) INCOR-USP: Giovanni M.V. Bellotti,Luiz Antônio M. César, João Fernando M. Ferreira, David Pamplona; 3 ) Hospital Universitário - USP: Rodolfo P. Albuquerque, Ariovaldo Marques, Carlos Eduardo Pompílio; 4) Santa Casa de Misericórdia, São Paulo: Roberto A. Franken, Valdir Golin; 5) Instituto Dante Pazzanese de Cardiologia, São Paulo: Júlio César Gizzi, Dalmo A. R. Moreira; 6) Hospital do Servidor Público Estadual, São Paulo: João Pimenta, Ney Valente; 7) Unicor, São Paulo: Ricardo F. Salvadori, Antonio Carlos Nogueira; 8) Santos (SP): Hermes T. Xavier, Luiz Fernando G. Silva; 9) Campinas (SP): Otávio R. Coelho, Cláudio Pinho; 10) Sorocaba (SP): Hudson França, José Roberto Maiello; 11) São José dos Campos (SP): Wilson Salgado $\mathrm{F}^{\mathrm{o}}$, Eduardo Costa; 12) Ribeirão Preto (SP): José Antonio Marin Neto, Marcelo G. Leal; 13) São José do Rio Preto (SP): Adalberto M. Lorga, Ricardo Sanches, Sílvio Roberto B. Alessi; 14) Marília (SP): João Carlos F. Braga, Benito Garbelini Jr; 15) Franca (SP): Ricardo de O. Bessa.

\section{References}

1. Lown B, Amarasingham R, Newman J. New method for terminating cardiac arrhythmias: use of synchronized capacitor discharge. JAMA 1962; 182: 548-55.

2. Kerber R, Martins J, Kienzle M, et al. Energy, current, and success in defibrillation and cardioversion: clinical studies using an automated impedance-based method of energy adjustment. Circulation 1988; 77: 1038-46.

3. Mehta PM, Reddy BR, Lesser J, Carson PE. Severe bradycardia following electrical cardioversion for atrial tachyarrhythmias in patients with acute myocardial infarction. Chest 1990; 97: 241-2

4. Ebrahimi R, Rubin AS. Electrical cardioversion resulting in death from synchronization failure. Am J Cardiol 1994; 74: 100-2.

5. Martin D, Mendelsohn ME, John RM, Loscalzo J. Cardioversion and other nonpharmacologic therapies. In: Atrial Fibrillation. Cambridge, USA: Blackwell Scientific Publications, 1994: 42-59.

6. Garcia Rubira JC, Romero D, Garcia JT, Lopez V, Cruz JM. Transient myocardial injury after electrical cardioversion. Int J Cardiol 19945; 46: 283-5.

7. Van Gelder IC, Crijns HJ, Van Der Laarse A, Van Gilst WH, Lie KI. Incidence and clinical significance of ST segment elevation after electrical cardioversion of atrial fibrillation and atrial flutter. Am Heart J 1991; 121: 51-6.

8. Figueiredo E. Relação custo-efetividade da cardioversão elétrica versus química, no tratamento da fibrilação atrial paroxística. Análise baseada na "intenção de tratar”. Tese de Doutorado. Universidade Federal de São Paulo - Escola Paulista de Medicina. 1997: 160 p.

9. de Paola AAV, Figueiredo E for the SOCESP Investigators. Chemical versus electrical cardioversion for treatment of atrial fibrillation: an intention-to-treat analysis. Pacing Clin Electrophysiol 1997; 20(supl.II): 1120.

10. de Paola AAV, Veloso HH for the SOCESP Investigators. Efficacy and safety of sotalol versus quinidine for the maintenance of sinus rhythm after conversion of atrial fibrillation. Am J Cardiol 1999; 84: 1033-7.

11. Veloso HH. Eficácia e segurança de sotalol versus quinidina na manutenção do ritmo sinusal após a reversão de fibrilação atrial. Tese de doutorado. Universidade Federal de São Paulo - Escola Paulista de Medicina, 1999: 174 p.

12. Bianconi 1, Mennuni M, Lukic V, Castro A, Chieffi M, Santini M. Effects of oral propafenone administration before electrical cardioversion of chronic atrial fibrillation: a placebo-controlled study. ??1996; 28: 700-6.

13. Oral H, Souza JJ, Michaud GF, et al. Facilitating transthoracic cardioversion of atrial fibrillation with ibutilide pretreatment. N Engl J Med 1999; 340: 1849-54.

14. Capucci A, Villani GQ, Aschieri D, Rosi A, Piepoli MF. Oral amiodarone increases the efficacy of direct-current cardioversion in restoration of sinus rhythm in patients with chronic atrial fibrillation. Eur Heart J 2000; 21: 66-73.

15. Veloso HH. Effects of oral sotalol administration before electrical cardioversion of persistent atrial fibrillation. Eur Heart J 2001 (no prelo).
16. Lown B. Electrical reversion of cardiac arrhythmia. BrHeart J 1967; 29:469-89.

17. Resnekov L, McDonald L. Appraisal of electroconversion in treatment of cardiac dysrhythmias. Br Heart J 1968; 30: 786-811.

18. Van Gelder IC, Crijns HJ, Van Gilst WH, Verwer R, Lie KI. Prediction of uneventful cardioversion and maintenance of sinus rhythm from direct-current electrical cardioversion of chronic atrial fibrillation and flutter. Am J Cardiol 1991; 68: 41-6.

19. Sermasi S, Marconi M, Cioppi F. Cardioversione elettrica di elezione della fibrillazione atriale non isolata nell'adulto: proposta di ottimizzazione della procedura. G Ital Cardiol 1995; 25: 1399-406.

20. Ricard P, Levy S, Trigano J, et al. Prospective assessment of the minimum energy needed for external electrical cardioversion of atrial fibrillation. Am J Cardio 1997; 79: 815-6.

21. Joglar JA, Hamdan MH, Ramaswamy K, et al. Initial energy for elective external cardioversion of persistent atrial fibrillation. Am J Cardiol 2000; 86: 348-50.

22. Georges J, Spentchian M, Caubel C, et al. Time course of troponin I, myoglobin, and cardiac enzyme release after electrical cardioversion. Am J Cardiol 1996; 78 825-7.

23. Allan J, Feld R, Russel A, et al. Cardiac troponin I levels are normal or minimally elevated after transthoracic cardioversion. J Am Coll Cardiol 1997; 30: 1052-6.

24. Neumayr G, Hagn C, Ganzer H, et al. Plasma levels of troponin T after electrical cardioversion of atrial fibrillation and flutter. Am J Cardiol 1997; 80: 1367-9.

25. Lévy S, Breithardt G, Campbell RWF, et al. on behalf of the Working Group on Arrhythmias of the European Society of Cardiology. Atrial fibrillation: current knowledge and recommendations for management. Eur Heart J 1998; 19: 1294-320.

26. Talajic M, MacDonald RG, Nattel S. Restoration of sinus rhythm in patients with atrial fibrillation. Can J Cardiol 1996; 12(suppl A): 29A-35A.

27. Wyse DG. Initial energy for electrical cardioversion of atrial fibrillation-is more better? Am J Cardiol 2000; 86: 324-5.

28. Guidelines for cardiopulmonary resuscitation and emergency cardiac care. Emergency Cardiac Care Committee and Subcommittees, American Heart Association. Part III. Adult advanced cardiac life support. JAMA 1992; 268: 2199-241

29. Dalzell GW, Anderson J, Adgey AA. Factors determining success and energy requirements for cardioversion of atrial fibrillation. Q J Med 1990; 76: 903-13.

30. Prystowsky EN, Benson Jr. DW, Fuster V, et al. Management of patients with atrial fibrillation: a statement for healthcare professionals from the Subcommittee on Electrocardiography and Electrophysiology, American Heart Association. Circulation 1996; 93: 1262-77. 